\title{
O PROJETO PEDAGÓGICO DO CURSO DE PEDAGOGIA DA FCT/UNESP: REFLEXÕES ACERCA DO ESTÁGIO E DA RELAÇÃO TEORIA-PRÁTICA
}

\author{
Mariana Felicio Silva de Oliveira, Célia Maria Guimarães \\ Universidade Estadual Paulista - FCT/UNESP, Presidente Prudente, SP. Agência Financiadora: CAPES. E-mail: \\ marianafelicioeduc@yahoo.com.br
}

\begin{abstract}
RESUMO
Este artigo objetiva analisar o projeto do curso de Pedagogia (2010-2014) da FCT/UNESP em relação à concepção, organização e estrutura do estágio e identificar se incide a intenção de se promover a articulação entre teoria e prática no decorrer do estágio. A pesquisa é qualitativa, utilizando-se como procedimento metodológico a análise documental na perspectiva da análise de conteúdo. Os resultados expressam a preocupação com a componente burocrática do estágio e indicam que a orientação quanto ao andamento deste é sempre de responsabilidade do professor orientador, embora não existam especificações de como e quando as orientações são realizadas. Há intenção declarada de articulação teórico-prática, mas não podemos afirmar o mesmo em relação à projeção de uma sistemática de estágio que corrobore tal desígnio.
\end{abstract}

Palavras-chave: Projeto Pedagógico. Estágio. Orientação. Pedagogia. Teoria e prática.

\section{THE EDUCATIONAL PROJECT OF THE EDUCATION COURSE OF FCT/UNESP: REFLECTIONS ON THE INTERNSHIP AND THE THEORY-PRACTICE INTERACTION}

\begin{abstract}
This article aims to analyze the Education course project (2010-2014) of FCT/UNESP in relation to its concept, organization and the internship structure and to identify if it focuses on the intention of promoting the articulation between theory and practice during the internship. The research is qualitative, using as a methodological procedure the document analysis from the perspective of content analysis. The results express a concern about the bureaucratic component of the internship and they indicate that the orientation as far as its progress is always the guiding teacher's responsibility, although there are no specifications on how and when the guidelines are carried out. There's a stated intention of theory and practice articulation, but we cannot say the same for the projection of an internship system which corroborates such plan.

Keywords: Graduate Education Program. Internship. Education. Teacher's training. Theory and practice.
\end{abstract}




\section{INTRODUÇÃO}

Esta pesquisa estrutura-se a partir da compreensão de que o estágio supervisionado precisa ser visto como atividade que articule a teoria e a prática para aprimorar a formação inicial docente. Isto porque uma das dificuldades e desafios centrais desta etapa de formação é o equacionamento da clássica relação entre teoria e prática. Muitas vezes, quando discutimos formação inicial de professores, de alguma maneira, estamos discutindo a relação entre as teorias e as práticas, pois este é o cerne e o alicerce desta formação.

Sobre isto, Gatti (2012, p. 2) afirma que a formação de professores nas universidades, de forma geral, ainda não considera com a devida importância a relação teoria e prática, pois “[...] a relação entre teorias e práticas colocada como necessária em nossas normatizações políticas sobre a formação de professores não se encontra refletida nos currículos praticados pelas instituições formadoras de professores.".

Assim, a visão da relação teoria e prática, na perspectiva deste estudo, é contrária à concepção de que o estágio é o momento prático apenas, uma vez que a prática deve ser intencionada à luz da teoria e necessita ser refletida, problematizada e até mesmo repensada. Portanto, a prática não pode ser desprovida da teoria, da reflexão, uma vez que "[...] a prática é a razão de ser da teoria, o que significa que a teoria só se constituiu e se desenvolveu em função da prática que opera, ao mesmo tempo, como seu fundamento, finalidade e critério de verdade. A teoria depende, pois, radicalmente, da prática." (SAVIANI, 2005, p. 262).

Temos o objetivo de analisar o projeto do curso de Pedagogia (2010-2014) da FCT/UNESP em relação à concepção, organização e estrutura do estágio e também identificar se incide, neste documento, a intenção de se promover a articulação entre conhecimentos teóricos e práticos no decorrer do estágio.

\section{METODOLOGIA}

A pesquisa se insere na abordagem qualitativa. Para a sua realização, utilizamos como procedimento metodológico a análise documental do projeto do curso de Pedagogia da FCT/UNESP, gestão de 2010 a 2012 (em vigor até 2014), na perspectiva da análise de conteúdo (BARDIN, 2011). O referido documento consta no site da universidade (http://www.fct.unesp.br/), acessado em 11 de dezembro de 2014.

De acordo com Bardin (2011), a análise documental é diferente da análise de conteúdo; contudo, é possível analisar um documento nesta perspectiva. Ao diferenciar a análise documental da análise de conteúdo, a pesquisadora menciona que, nesta última, há o recorte da informação, a 
divisão em categorias, a comparação e a indexação, no entanto, o principal é a análise da mensagem.

Em vista disso, a análise do projeto do curso de Pedagogia, nesta pesquisa, não se limita a representar o conteúdo sob uma forma diferente da original para facilitar a sua consulta e referenciação, mas evidenciar os indicadores nele contidos de forma a auxiliar a compreensão da problemática de estudo: a abordagem da teoria e da prática no estágio.

\section{RESULTADOS}

O projeto do curso de Pedagogia da FCT/UNESP consta no site da instituição e possui quinze páginas, com a seguinte estrutura: introdução; objetivos (do curso); perfil profissional; matriz curricular; disciplinas optativas; estágios supervisionados; atividades Acadêmico-CientíficoCulturais (AACC); núcleos de estudos integradores; grupos de pesquisa; eventos; linhas de pesquisa do Departamento de Educação e corpo docente.

Essa organização textual foi elaborada pelo Conselho de Curso de Pedagogia, na gestão 2010-2012 (que esteve em vigor até 2014) e é resultado de debates realizados pelo Conselho de Curso, Conselho de Departamento, avaliações do curso e participação de estudantes de Pedagogia.

O curso forma o professor de Educação Infantil e anos iniciais do Ensino Fundamental e o Gestor Educacional ao longo de quatro anos, tanto para o período vespertino quanto para o noturno. Os objetivos gerais da formação desdobram-se em:

1- Possibilitar uma sólida fundamentação teórico-metodológica com base nos pressupostos filosóficos, históricos, sociológicos e psicológicos da educação visando preparar os estudantes para o exercício profissional;

2- Proporcionar formação teórico-prática, através de disciplinas metodológicas que desenvolvem diferentes componentes curriculares e práticas de ensino, integradas às discussões de sala de aula, a profissionalização do licenciado em Pedagogia para a Educação da Infância de 0 a 12 anos, bem como, para a participação na gestão de processos educativos e na organização e funcionamento de sistemas e instituições de ensino em espaços escolares e não escolares.

3- Oportunizar ao aluno compreender a educação como fenômeno social ajudando-o a conhecer, refletir, denunciar, criticar e anunciar sobre a realidade social. (UNIVERSIDADE ESTATUAL PAULISTA, 2010, p. 3, grifo nosso).

Em seguida aos objetivos, o documento apresenta o perfil do pedagogo e afirma que o egresso estará habilitado a:

- Conceber, executar e avaliar projetos educacionais/pedagógicos (coletivos e interativos), articulando ação-reflexão-ação (teoria e prática); 
- Participar no âmbito político e social como crítico/reflexivo, como por exemplo, no Conselho Municipal de Educação;

- Exercer a docência na Educação Infantil, nos anos iniciais do ensino fundamental, inclusive no que concerne às metodologias da Alfabetização, da Matemática, da História, da Geografia, da Comunicação e Expressão e de Ciências, que fazem parte do currículo de formação de professores, em nível médio;

- Planejar e executar currículos e programas de ensino e/ou atividades para as séries iniciais do ensino fundamental e educação infantil;

- Avaliar cursos e programas de ensino e/ou atividades em ambientes escolares e não escolares, assim como, em programas sociais com caráter educativo, em hospitais, brinquedotecas, etc.

- Assessorar técnica e pedagogicamente o desenvolvimento do ensino das disciplinas e/ou atividades para as Secretarias municipais de Educação, para as ONGs e instituições escolares e não escolares;

- Elaborar e coordenar projetos para o ensino e/ou atividades para Instituições governamentais e não governamentais;

- Participar de pesquisas pedagógicas de acordo com as necessidades da região;

- Atuar como diretor, coordenador e/ou supervisor de ensino.

(UNIVERSIDADE ESTADUAL PAULISTA, 2010, p. 5, grifo nosso).

A matriz curricular do curso possui um total de 2.985 horas de atividades formativas e 300 horas de estágio supervisionado e prática de ensino, divididas em 100 horas para gestão, 100 horas para Educação Infantil (divididas entre creche e pré-escola) e 100 horas para anos iniciais do Ensino Fundamental.

Em relação ao estágio supervisionado, registra-se que este deve proporcionar a integração entre teoria e prática, oferecendo ao estagiário o conhecimento das escolas e de seu funcionamento.

Sobre a realização do estágio, o documento deixa claro que:

A parte burocrática (orientação quanto ao preenchimento de documentos, encaminhamento de listas de alunos à SEDUC- Secretaria de Educação Municipal) ficará centrada em um docente, mas haverá um rodízio anual entre eles para o exercício desta função [...] Entretanto, a orientação sobre as atividades a serem desenvolvidas durante o estágio será feita e avaliada por cada docente responsável por sua disciplina metodológica. (UNIVERSIDADE ESTADUAL PAULISTA, 2010, p. 5, grifo nosso).

Ao procurar alcançar nosso segundo objetivo específico, qual seja refletir se existe no projeto do curso a intenção de se promover a articulação entre conhecimentos teóricos e práticos no decorrer do estágio, constatamos que há, nos objetivos gerais deste curso, a preocupação em 
proporcionar formação teórico-prática através de disciplinas metodológicas que desenvolvem diferentes componentes curriculares e práticas de ensino.

Particularmente no que diz respeito ao estágio supervisionado, o documento aponta que:

\begin{abstract}
A Prática de Ensino e o Estágio Supervisionado devem assegurar a integração entre teoria e prática na formação do educador, oportunizando ao futuro profissional o conhecimento das escolas e seu funcionamento cotidiano, levando o aluno a compreender o processo de concepção, construção e gestão de situações próprias do ambiente escolar. (UNIVERSIDADE ESTADUAL PAULISTA, 2010, p. 5, grifo nosso).
\end{abstract}

\title{
DISCUSSÃO
}

De acordo com nossa leitura, interpretação, reflexão e inferência, tendemos a algumas afirmações. A análise demonstra que o projeto do curso em questão se preocupa com a componente burocrática do estágio, ou seja, com a documentação (preenchimento de papéis e assinaturas). Por outro lado, a orientação quanto ao andamento do estágio e os momentos de reflexão e teorização do trabalho pedagógico são sempre de responsabilidade do professor da disciplina de metodologia.

Não podemos afirmar, até o momento, que a exclusiva preocupação quanto ao fluxo do estágio esteja direcionada à componente burocrática (preenchimento de documentos, como termos de compromisso, plano do estágio, diário de bordo e documentos solicitados pela SEDUC). Porém, o estágio "[...] não pode ser constituído de forma burocrática, com preenchimentos de fichas e desprovido de investigação." (BARREIRO; GEBRAN, 2006, p. 26). Caso esta realidade vigore com excessiva extensão, o curso não preparará devidamente o professor.

Também verificamos que o projeto não especifica como e quando as orientações de estágio são realizadas pelos formadores: não são mencionados nem a forma nem o momento das orientações. Diante disso, podemos inferir que não há, no projeto do curso, uma proposta de estágio que contemple este tipo de procedimento, o que proporciona ao responsável pela disciplina de metodologia e, ao mesmo tempo, orientador do estágio, autonomia para agir conforme desejar.

Dado semelhante foi encontrado nas pesquisas de diagnóstico de Gatti $(2010,2014)$ que, ao analisar diversos projetos dos cursos de Pedagogia no Brasil, afirma que:

[...] não se obtiveram evidências, nos estudos a que nos referimos, sobre como esses estágios vêm sendo de fato realizados, pois os dados referentes a eles padecem de uma série de imprecisões, que praticamente inviabilizam uma análise do que acontece realmente nesses espaços de formação a partir apenas dos currículos documentados. Apesar disso, as observações largamente difundidas sobre o funcionamento das licenciaturas e estudos 
específicos publicados nos autorizam a sugerir que a maior parte dos estágios envolve atividades de observação. (GATTI, 2010, p. 1371, grifo nosso).

Embora não haja uma proposta explícita acerca do estágio, podemos deduzir a sua existência baseada em observação e entrega de relatório pelos estudantes.

Não defendemos um modelo específico de estágio para formar o professor, mas nos parece interessante que o projeto político pedagógico indique um planejamento no qual se ofereçam condições materiais objetivas para a realização de um estágio que articule teoria e prática. Assim, podemos afirmar que o projeto de curso analisado é retrógrado, pois ainda não oferece uma proposta para o estágio na formação inicial do professor.

Procedendo a uma análise "ao pé da letra", parece que se entende que o estágio curricular supervisionado precisa garantir a união entre a teoria e a prática na formação do professor, no entanto, o texto não apresenta uma diretriz, não há orientações sobre como e quando realizar o binômio teoria-prática de forma articulada.

Portanto, é declarada a importância de se unir teoria e prática, porém, sem a preocupação objetiva de oferecer uma proposta concreta para que isto seja, de fato, alcançado. Gatti (2010) verificou exatamente isso na maioria dos cursos de Pedagogia do Brasil e afirma que os projetos pedagógicos dos cursos mostram que há um idealismo perceptível nas suas proposições, mas as ideias não se concretizam na formação realmente oferecida. Ou seja, teorias e práticas não se mostram integradas até hoje.

\section{CONCLUSÃO}

Podemos deduzir, em conformidade com Gatti (2014), que o estágio, no curso de Pedagogia investigado, é realizado como na maior parte das universidades: observação e entrega de relatório.

Finalizamos, então, refletindo acerca dos contributos de Pimenta e Lima (2004) ao defenderem a mudança na atual conjuntura do estágio na formação de professores. Em consonância com as autoras, entendemos que é preciso obter um projeto pedagógico mais articulado com a instituição escolar, estabelecendo parcerias, e que todos os formadores do curso possam oferecer contributos ao graduando em relação à teoria-prática, e não unicamente o professor orientador de estágio.

Contudo, estamos cientes de que ainda é possível pensarmos em outros caminhos para a melhoria do complexo binômio teoria-prática. Certamente, muitas outras reflexões e análises 
devem ser realizadas sobre como estão sendo abordadas a teoria e a prática nos cursos de formação de professores. Essa análise, em momento algum, procurou esgotar tal temática, nem mesmo fechar as questões ou propor respostas corretas, definitivas, mas estimular novas perguntas, novas práticas, novas leituras, novas reflexões e novas possibilidades.

\section{REFERÊNCIAS}

BARDIN, L. Análise de Conteúdo. Tradução Luís Antero Reto, Augusto Pinheiro. 3. reimp. São Paulo: Edições 70, 2011.

BARREIRO, I. M. F; GEBRAN, R. A. Prática de Ensino e Estágio Supervisionado na Formação de Professores. São Paulo: Avercamp, 2006.

GATTI, B. A. A formação inicial de professores para a educação básica: as licenciaturas. Revista USP, São Paulo, n. 100, p. 33-46, dez./jan./fev. 2014. Disponível em:

<http://www.revistas.usp.br/revusp/article/view/76164/79909>. Acesso em: 02 mai. 2015.

. Análises pedagógico-curriculares para os cursos de licenciatura vinculados às áreas de artes, biologia, história, língua portuguesa, matemática e pedagogia no âmbito da Uab e Parfor. Documento Técnico. Brasília: Unesco/MEC/Capes, 2012.

. Formação de professores no Brasil: características e problemas. Educação \& Sociedade, Campinas, v. 31, n. 113, p. 1355-1379, out./dez. 2010. Disponível em:

<http://www.cedes.unicamp.br>. Acesso em: 25 jun. 2014.

PIMENTA, S. G.; LIMA, M. S. L. Estágio e Docência. São Paulo: Cortez, 2004.

SAVIANI, D. Pedagogia histórico crítica: primeiras aproximações. 9. ed. Campinas: Autores Associados, 2005.

UNIVERSIDADE ESTADUAL PAULISTA. FACULDADE DE CIÊNCIAS E TECNOLOGIA. Projeto do Curso de Pedagogia (2010-2014). Presidente Prudente: FCT/UNESP, 2010. 